\title{
Calving location preference and changes in lying and exploratory behavior of preparturient dairy cattle with access to pasture
}

\author{
E. M. Edwards, ${ }^{1}$ P. D. Krawczel, ${ }^{1} \oplus$ H. M. Dann, ${ }^{2} \odot$ L. G. Schneider, ${ }^{1}$ B. Whitlock, ${ }^{1,3} \oplus$ and K. L. Proudfoot ${ }^{4 *} \oplus$ \\ ${ }^{1}$ Department of Animal Science, University of Tennessee, Knoxville 37996 \\ ${ }^{2}$ William H. Miner Agricultural Research Institute, Chazy, NY 12921 \\ ${ }^{3}$ Department of Large Animal Clinical Sciences, University of Tennessee, Knoxville 37996 \\ ${ }^{4}$ Veterinary Preventive Medicine, Ohio State University, Columbus 43210
}

\begin{abstract}
The objectives of this study were to (1) describe the calving location of dairy cattle given access to a pasture and barn; (2) identify factors associated with calving location; and (3) compare the lying and exploratory behavior of cows in the $24 \mathrm{~h}$ before calving and a previous day. Seventy-two Holstein dairy heifers and cows ( $\mathrm{n}=$ 36 nulliparous and $\mathrm{n}=36$ primiparous and multiparous combined) were housed in a covered bedded-pack barn $\left(167.4 \mathrm{~m}^{2}\right)$ with free access to 2.1 ha of pasture. The composition of the group was dynamic, because cows were moved in weekly at $19 \pm 6 \mathrm{~d}$ [mean \pm standard deviation (SD)] before their calving date, and were removed immediately after calving. To facilitate data collection, we divided the environment into 9 sections, including the barn (section 1; $167.4 \mathrm{~m}^{2}$ ), 7 sections of open pasture (sections 2 to $8 ; 2,402 \pm 60 \mathrm{~m}^{2}$ ), and 1 section of pasture surrounded by natural forage cover (section $9 ; 3,593 \mathrm{~m}^{2}$ ). We then collapsed these 9 sections into 3 distinct areas for further analysis: the barn, open pasture, and natural forage cover. Animals were fitted with accelerometers to measure lying time, lying bout duration, lying bouts, and steps for the $24 \mathrm{~h}$ before calving (calving day) and a similar $24 \mathrm{~h}$ period 4 to $11 \mathrm{~d}$ (median $=7$ ) before calving (baseline day). We included parity (nulliparous vs. primiparous and multiparous) and heat stress [no heat stress $=$ temperaturehumidity index $(\mathrm{THI}) \leq 68$ vs. heat stress $=$ THI $>68$ and $\leq 79$ ] in all analyses; we included time of day and group composition as additional factors that may have affected calving location. We determined exploratory behavior using 10 min instantaneous scan sampling collected from video. At each scan, we recorded the section (1 to 9 ) the cow or heifer was located in, and then calculated the minimum number of sections that
\end{abstract}

Received July 5, 2019.

Accepted February 11, 2020.

*Corresponding author: proudfoot.18@osu.edu could be crossed between successive scans. Of the total sample, $39 \%$ calved in the barn, $26 \%$ calved in the open pasture, and $35 \%$ calved in the area with natural forage cover. Nulliparous heifers and those calving when heat stress was low (THI $\leq 68)$ selected the area with natural forage cover more frequently than the barn. On the calving day, cows spent more time lying down with more short bouts of lying, and crossed more sections compared with the baseline day. Steps were affected by an interactive effect of day, parity, and heat stress; nulliparous heifers took more steps on the calving day during conditions of heat stress compared with no heat stress. Results indicate that cows and heifers had different preferences for their environment at calving, and when provided access to pasture, both changed their lying and exploratory behavior on the day of calving compared with a previous day.

Key words: transition, outdoor, calving behavior

\section{INTRODUCTION}

Labor in dairy cows is thought be painful (Mainau and Manteca, 2011) and may result in complications that can increase morbidity and mortality in both the dam and her calf (Lombard et al., 2007; Mee, 2008). Considerable research has improved the nutrition, management, and housing of dairy cows before and after they give birth (reviewed in Overton and Waldron, 2004 and Sepúlveda-Varas et al., 2013). However, most of this research has focused on the 3 wk before to the 3 wk after calving (the "transition" period); less work has assessed the proper housing and management of cows just before and during labor. A better understanding of the behavior of cows before labor is a useful step for designing and managing calving facilities from the perspective of the cow.

When they are kept indoors or outdoors, cows change their behavior as calving approaches. For example, some dairy cattle will separate from the herd and select a secluded birthing site (Lidfors et al., 1994; Proudfoot et al., 2014a,b). When kept on pasture, beef and dairy 
cows will distance themselves 25 to $1,250 \mathrm{~m}$ on the day of calving and seek out secluded areas of forage cover (i.e., trees and bushes), hollowed ground, and dry, soft ground (Lidfors et al., 1994; Flörcke and Grandin, 2014). When housed indoors in an individual maternity pen, cows with access to a covered area will use the secluded space to give birth, especially when they are calving during the day (Proudfoot et al., 2014b). When housed with a partner, cows are less likely to use a secluded space, but opt to separate from their partners from $8 \mathrm{~h}$ before calving (Proudfoot et al., 2014b). Thus, housing cows in groups may influence calving location preferences.

Research on cows housed indoors and on pasture has also determined that cows will change their lying behavior as calving approaches. For example, when cows give birth in an indoor maternity area, they increase their lying bouts or "restlessness" as calving approaches (Jensen, 2012; Rice et al., 2017). This increase in restlessness may be due to discomfort from myometrial and abdominal contractions (Mainau and Manteca, 2011), or it may be an expression of exploration, as the cow looks for an adequate space to give birth (Rørvang et al., 2018b). Black and Krawczel (2016) compared the behavior of cows kept indoors in individual maternity pens and those kept on pasture and found that cattle on pasture transitioned between lying and standing more often at calving than those kept indoors. The authors suggested that this finding was evidence that pasture is more comfortable than indoor environments, allowing cows to express their behavior more freely.

Although lying behavior changes have been documented in both indoor and pasture-kept dairy cows, little is known about how cows explore their environment at calving as they seek a suitable place to give birth. In lactating cattle housed in a free stall, providing extra space to cows encouraged them to walk greater distances (Telezhenko et al., 2012), but to our knowledge no research has determined the effect of space and environment on cow exploration and movement before calving. As well, research is still needed to determine if cattle prefer pasture environment or a barn, and what factors affect the choice of calving location in a more natural setting.

The objectives of this study were to (1) describe the calving location of dairy cattle given access to a pasture and barn; (2) determine factors associated with calving location preference [e.g., parity, temperature-humidity index (THI), time of day, stocking density, composition of the group]; and (3) compare the lying and exploratory behavior of cows in the $24 \mathrm{~h}$ before calving ("calving day") and a previous "baseline" day.

\section{MATERIALS AND METHODS}

All animal procedures were approved by the University of Tennessee Institutional Animal Care and Use Committee (Protocol \#2399-1115). This study was conducted at the University of Tennessee's Little River Animal and Environmental Unit (Walland, TN; $\left.35^{\circ} 46^{\prime} 5.8116^{\prime \prime} \mathrm{N}, 83^{\circ} 50^{\prime} 55.446^{\prime \prime} \mathrm{W}\right)$ from July to December 2016 .

\section{Animals, Housing, and Management}

This study included 72 Holstein dairy heifers and cows ( $\mathrm{n}=36$ nulliparous, $\mathrm{n}=19$ primiparous, and $\mathrm{n}=17$ multiparous; both primi- and multiparous animals will be referred to as "multiparous"). Cattle were housed in a covered bedded-pack barn $\left(167.4 \mathrm{~m}^{2}\right)$ with free access to 2.1 ha of pasture (Figure 1). Animals were moved into the environment $19 \pm 6 \mathrm{~d}$ [mean \pm standard deviation (SD)] before their actual calving date and removed after calving. New cohorts were added weekly; thus, the social composition of the group was dynamic. On average, $3 \pm 5$ (mean $\pm \mathrm{SD}$ ) cows and heifers entered the study each week. The average group size was 11, but ranged from 1 to 18 cows and heifers throughout the study. At 2 points, only 1 animal was in the pasture, but a new group of cattle was moved into the environment within $24 \mathrm{~h}$ to prevent cattle from calving alone 3 and $15 \mathrm{~d}$ before calving). No cows were alone on the pasture at calving or during any of our measurements before calving. On average, animals spent $19.4 \pm 5.9 \mathrm{~d}$ (mean $\pm \mathrm{SD}$; range $=7$ to $34 \mathrm{~d}$ ) in the environment before giving birth.

To facilitate data collection, the environment was divided into 9 sections (Figure 1): the barn (section 1; $167.4 \mathrm{~m}^{2}$ ), the areas of open pasture with no tree cover (sections 2 to 8 ; approximately $2,402 \pm 60 \mathrm{~m}^{2}$; mean $\pm \mathrm{SD})$; and an area on the far end of the pasture with natural forage cover, including tall grass and tree cover. Section 9 was slightly larger than the other pasture sections $\left(3,593 \mathrm{~m}^{2}\right)$, because features of this area clearly differentiated it from the other sections: (1) this part of the pasture was not maintained, which provided taller grass for more potential cover; (2) trees surrounded the perimeter; and (3) the narrowing of the fence line at the starting point of the section provided a clear separation from the rest of the pasture. The pasture was divided using Quik Shot Spray Paint (LA-CO Industries Inc., Elk Grove Village, IL). For some analyses, we collapsed these 9 sections into 3 discrete areas: the barn (section 1 ), open pasture (sections 2 to 8 ), and pasture with natural forage cover (section 9). 


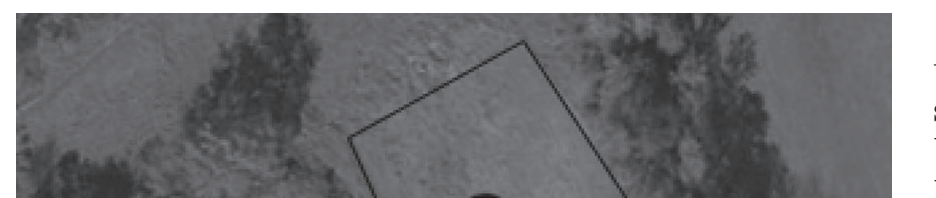

The barn was deep-bedded with straw and equipped with 23 headlocks for feeding. Cattle were fed a TMR sufficient to meet the nutritional requirements laid out by the NRC (2001) once daily at $1600 \mathrm{~h}$, and had ad libitum access to hay in the barn. The straw-beddedpack was cleaned monthly as part of normal farm protocols. Two automatic waterers (Thrifty-King CT4-2000; Ritchie Industries Inc., Conrad, IA; 1 in the barn and 1 on pasture; Figure 1) provided cattle with ad libitum access to water.

Artificial, V-shaped "hides" $(\mathrm{n}=6)$ were included in the areas of open pasture (sections 2 to 8 ) and were built by bolting corrugated metal sheets to 1 side of a metal gate $(3.7 \times 1.8 \mathrm{~m})$ and connecting 2 metal gates. Hides were placed in sets of 2 throughout the pasture to serve as alternative areas for cows and heifers to seclude themselves at calving (Proudfoot et al., 2014a,b; Rørvang et al., 2018a). A pair of hides was placed $5 \mathrm{~m}$ apart, opened away from each other, with the opening also measuring $5 \mathrm{~m}$. The hides were rotated weekly between sections; one week, hides would be in sections 3,6 , and 7 , and the next week in sections 4,5 , and 8 .

Farm staff observed cattle every 4 to $6 \mathrm{~h}$ to monitor for signs of labor (i.e., frequent posture changes; pawing and sniffing the ground; raised tail; and signs of stage 2 labor, including abdominal contractions and presence of the amniotic sac or calf feet outside the vulva). To facilitate observations at night, farm staff drove through the pasture and used the vehicle headlights. While cattle were in labor, farm staff did not intervene with calving unless the animal showed signs of requiring assistance (i.e., prolonged straining and no progression of stage 2 labor). Calving difficulty was scored using a 5 -point scale $(1=$ no problems, $2=$ slight problems, $3=$ needed assistance, $4=$ considerable force used, and $5=$ extreme difficulty). Farm staff also recorded the approximate time and location of calving for each animal. Calves were removed from the cow or heifer within approximately $1 \mathrm{~h}$ of birth, and the cow or heifer was moved into a freestall barn approximately $2 \mathrm{~h}$ after calving.

Figure 1. Aerial view of the study environment at the University of Tennessee's Little River Research and Environmental Unit. Cattle were housed in the covered bedded-pack barn with free access to pasture. To facilitate date collection, we divided the environment into 9 sections, including the barn (section $1 ; 167.4 \mathrm{~m}^{2}$ ), 7 sections of "open pasture" (sections 2 to $8 ; 2,402 \pm 60 \mathrm{~m}^{2}$ each, mean $\pm \mathrm{SD}$ ), and 1 section of pasture surrounded by "natural forage cover" (section 9; 3,593 $\mathrm{m}^{2}$ ). We then collapsed these 9 sections into 3 distinct areas for further analysis: the barn, open pasture, and natural forage cover. Solid lines denote fencing, dashed lines denote division of the sections, dots indicate cameras, and triangles indicate automatic waterers. Image obtained from Google Earth (Google, Mountain View, CA).

\section{Behavioral Data Collection}

Calving Location. Calving location was recorded using eleven 1.0-Megapixel Outdoor IP67 Bullet Cameras (Amcrest, Houston, TX) mounted on wooden poles $4 \mathrm{~m}$ above the ground. Cameras had infrared light-emitting diode lights to facilitate night viewing. One camera was placed in the barn, and 10 were placed along the fence line of the pasture (Figure 1). Digital video data were saved continuously to 2 digital video recorders (8-channel 720p HDCVI; Amcrest) and transferred to a 6-TB external hard drive (Seagate, Cupertino, CA) daily. 
Video data were used to determine the "calving section" for each cow (1 through 9; Figure 1) and the time of calving, defined as the time the animal stood up after calving or if the animal was already standing at completion of stage 2 labor (delivery of the calf). Although it would have been ideal to define calving time as the moment the calf's hips were expelled (Proudfoot et al., 2014a,b), this event was not always detected on video. Due to camera placement in sections 1 and 9 , the exact calving time for some cattle $(\mathrm{n}=31)$ could not be determined. The farm's estimated time of calving was used for these animals. To ensure that the estimated times were close to the actual time of calving, we used descriptive statistics to compare the estimated and actual times of calving for the 34 cows and heifers for whom both the farm staff's estimates and actual calving times from video were collected. For animals with missing video, their calving section could be determined using footage from other cameras, because cows and heifers were observed entering a section before calving, and leaving that section when the farm staff was collecting their calf.

To determine whether cows and heifers had a specific preference for a calving section and did not spend all of their time in that area before calving, we compared the animals' location in the $24 \mathrm{~h}$ before calving (calving day) to the same $24 \mathrm{~h}$ period on a baseline day $7.6 \pm$ $1.2 \mathrm{~d}$ (mean $\pm \mathrm{SD}$ ) before calving using 10-min scan sampling. The baseline day was specifically chosen to be a day with similar temperature and humidity levels as the calving day to reduce any variations in behavior due to weather. At each scan, the section of each focal animal was recorded. The scan data were used to calculate the percentage of time that cows and heifers were in their calving section on the calving and baseline days.

Lying and Exploratory Behavior. Lying and exploratory behaviors were measured on the same calving and baseline days as calving location preference. To record lying behavior, cattle were fitted with an accelerometer (IceTag; IceRobotics, Edinburgh, UK) on their hind leg upon entering the study, and accelerometers were removed $14 \mathrm{~d}$ after calving. Accelerometers automatically measured lying time $(\mathrm{h} / \mathrm{d})$, lying bout duration (min/bout), lying bouts (no./d), and steps (no./d). All lying bouts $2 \mathrm{~min}$ or less were removed (Mattachini et al., 2013).

Exploratory behaviors were recorded using continuous video data. One trained observer recorded exploratory behavior in cows using 10-min scan sampling of the video data. To determine how cows and heifers were using their space before calving, we recorded which of the 9 sections (Figure 1) the majority of a cow's body was in at each 10-min scan. To determine how cows and heifers used the space given to them, we calculated the minimum number of sections that needed to be crossed for an animal to move from their previous section to a new section at each 10-min scan and summed the findings for each animal and day (no./d; adapted from Telezhenko et al., 2012).

\section{Temperature and Humidity Measurements}

A weather station at University of Tennessee's Little River Animal and Environmental Unit collected hourly temperature and humidity data. These data were used to calculate the hourly and mean daily THI (NOAA, 1976) for calving and baseline days. We then categorized each day based on THI for the likelihood cows would be experiencing mild to moderate heat stress conditions on that day (THI $\leq 68=$ no heat stress, and THI $>68$ and $\leq 79=$ heat stress; Cook et al., 2007). Cows were assigned one of these categories summarized for each day for their calving and baseline days.

\section{Exclusion Criteria}

If a cow or heifer calved within $7 \mathrm{~d}$ of entering the study, we assumed she did not have adequate time to become familiar with all areas of the barn and pasture, so she was excluded. Cows or heifers were also excluded if they were considered lame on a 5 -point locomotion scoring system (score of 3 or above; $1=$ sound, $2=$ imperfect locomotion, $3=$ lame, $4=$ moderately lame, and $5=$ severely lame) on the day of entry into the study or the day of calving. Cows or heifers were excluded if they had twins, or experienced an abortion or a dystocia (a calving that required the assistance of farm staff or a veterinarian; score of 5 on a 5 -point scale), because these animals were moved into the barn for assistance. Cows or heifers were excluded from the lying behavior analysis if their accelerometers malfunctioned. Finally, cows or heifers were excluded if they experienced a disturbance on the day of calving outside of normal farm protocols.

\section{Statistical Analysis}

This study had an observational design, and the experimental unit was the animal. All statistical analyses were performed using SAS software (version 9.4; SAS Institute Inc., Cary, NC). Significance was declared at $P<0.05$. Data from all models were visually assessed for normality of residuals and homogeneity of variance.

Descriptive Statistics. Descriptive statistics were used to summarize the percentage of cows that calved 
in each of the 9 sections, as well as in each of the 3 designated areas (barn, open pasture, and natural forage cover). Descriptive statistics were also used to describe the difference between the farm staff's estimate of calving time and the actual calving time for the cows and heifers that had these data available $(\mathrm{n}=$ 34). Temperature and THI were analyzed to provide a description of the climate throughout the study.

Calving Location Preference. To determine whether cows and heifers used the environment differently on their calving day compared to a baseline day, we analyzed the percentage of time each animal spent in their calving section on the calving day and baseline day using a mixed model ANOVA (PROC GLIMMIX). The model included the fixed effects of parity (nulliparous vs. multiparous), day (calving vs. baseline), and calving section (1 through 9 ), as well as all possible interactions. Manual backward elimination was used to remove any nonsignificant interactions from the model. Animal nested within parity was included as a random effect. Mean separation was performed using Fisher's least significant difference with the DIFFS option in LSMEANS.

Factors that Affected Calving Location. To determine what factors would affect an animal's choice of calving section, we used multinomial logistic regression (PROC GLIMMIX). Because a limited number of calvings occurred in the open pasture (section 2 through 8 ), we used the 3 discrete areas for this analysis rather than calving section (e.g., barn, open pasture and natural forage cover). The model included the following predictors: parity (nulliparous vs. multiparous), THI (mean THI calculated over the $8 \mathrm{~h}$ before calving), time of day (a.m. vs. p.m.), mean stocking density, stocking density on the day of calving, and cow-to-heifer ratio (ratio of the number of primiparous and multiparous cows to nulliparous heifers in the environment at the time of calving), as well as all possible interactions. We specified a multinomial distribution and a generalized logit link for nominal response variables. Manual backward elimination was used to remove any nonsignificant factors from the model. The barn area served as the reference in the models, as this type of housing is more common than pasture for housing cattle at calving.

Lying and Exploratory Behavior. To determine differences in lying behavior between the calving and baseline days, we first summarized behavioral data were to create one value for each animal and day. Mixed model ANOVA were performed using GLIMMIX procedures to test the fixed effects of day (calving vs. baseline), parity (nulliparous vs. multiparous), THI (heat stress vs. no heat stress), and all interactions on lying behaviors. The response variables of interest were lying time, lying bout duration, number of lying bouts, and number of steps taken by cows. Backward manual elimination was used to remove all nonsignificant interactions. Animal nested within parity was included as a random effect.

To determine if cows or heifers changed their exploratory behavior and use of space before calving, the number of sections crossed collected using 10-min scan sampling were summarized for each animal and day. Mixed model ANOVA were performed using GLIMMIX procedures to test the fixed effects of day (baseline vs. calving), parity (nulliparous vs. multiparous), THI (heat stress vs. no heat stress), and all interactions on the number of sections crossed per day. Animal nested within parity was included as a random effect. Backward manual elimination was used to remove all nonsignificant $(P>0.05)$ interactions.

\section{RESULTS}

\section{Inclusion and Descriptive Data}

Of the 72 animals originally included in the study, 1 was excluded due to lameness, 5 were excluded due to dystocia, and 1 was excluded because she experienced disturbance on the day of calving outside of the normal farm protocol (she escaped from the pasture and was moved back in when she was already in labor). Thus, 65 animals $(\mathrm{n}=32$ nulliparous heifers and $\mathrm{n}=33$ primiand multiparous cow) were included in the analyses. An additional animal was excluded from the lying behavior analysis because of a malfunctioning accelerometer.

We found a difference of $49.7 \pm 51.6$ min (mean \pm SD; range 0 to $261.1 \mathrm{~min}$ ) between the farm staff's estimated time of calving and actual calving times confirmed by video $(\mathrm{n}=34)$. Throughout the study, temperature was $16.4 \pm 9.9^{\circ} \mathrm{C}$ (range -9.2 to $34.5^{\circ} \mathrm{C}$ ) and THI was $60.0 \pm 14.4$ (range 18.1 to 81.8 ).

Of the 65 calving events, $25(39 \%)$ occurred in the barn, $23(35 \%)$ occurred in the area with natural forage cover, and $17(26 \%)$ occurred in the open pasture (7, 2,3 , and 5 calvings occurred in sections $4,6,7$, and 8, respectively; no calvings occurred in sections 2,3 , or 5). Of those that calved in the open pasture, only 2 (3\%; both multiparous) calved within 1 cow's length of an artificial hide on pasture; thus, we performed no analyses to determine the factors associated with calving near a hide.

\section{Calving Location Preference}

After adjusting for section and parity, we found that all cattle spent a greater percentage of their day in their calving section on their calving day compared 
with their baseline day ( 24.9 vs. $12.1 \pm 2.3 \%$ of day; $P$ $<0.001)$.

\section{Factors Affecting Calving Location}

Parity $(P=0.02$; Figure 2$)$ and THI $(P=0.02)$ were each associated with the selection of calving section. Primiparous and multiparous cows selected the barn more frequently for calving, and nulliparous heifers selected the natural forage cover more frequently. Adjusting for THI effects, compared with the barn (reference), nulliparous heifers were more likely to calve in the natural forage cover than cows [odds ratio $(\mathbf{O R})=6.9 ; 95 \%$ CI: 1.8-26.4]. Heifers did not exhibit higher or lower odds of calving in the open pasture versus the barn compared with cows $(\mathrm{OR}=2.7 ; 95 \%$ CI: 0.7-10.2). Cattle were more likely to calve in the natural forage area than the barn when THI was 68 or less than when THI exceeded 68 (OR $=7.4 ; 95 \%$ CI: $1.2-45.1)$. We found no difference in likelihood of calving in the open pasture compared to the barn between low or high THI $(\mathrm{OR}=0.6 ; 95 \%$ CI: $0.2-2.1])$. Time of day $(P=0.25)$, mean stocking density $(P=0.41)$, stocking density at calving $(P=0.97)$, and cow-to-heifer ratio $(P=0.62)$ were not associated with the selection of calving location.

\section{Lying and Exploratory Behavior}

Lying time was lower on the calving day than on the baseline day $(P<0.001$; Figure 3$)$. Regardless of day, nulliparous animals spent $2 \mathrm{~h}$ less time lying than multiparous cows $(7.6$ vs. $9.7 \pm 0.3 \mathrm{~h} / \mathrm{d}$; mean $\pm \mathrm{SEM}$;

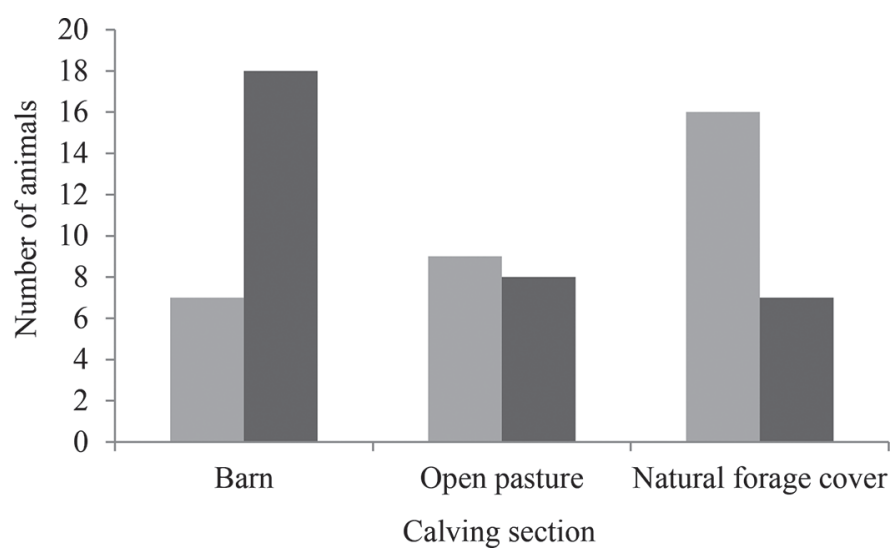

Figure 2. The number of nulliparous heifers (light gray bars) and primi- and multi-parous cows (combined; dark gray bars) that calved in each area of the study environment. The barn area included a strawbedded pack $\left(167.4 \mathrm{~m}^{2}\right)$; the open pasture area included 8 sections of pasture without any tree or forage cover (mean \pm SD 2,402 $\pm 60 \mathrm{~m}^{2}$ each); and the area of pasture with natural forage cover included tall grass and tree cover $\left(3,593 \mathrm{~m}^{2}\right)$.
$P<0.001$ ), and animals experiencing heat stress spent less time lying compared with those not experiencing heat stress $(7.7$ vs. $9.6 \pm 0.3 \mathrm{~h} / \mathrm{d} ; P<0.001)$.

The number of lying bouts was higher, and mean lying bout duration was shorter on the calving day than on the baseline day $(P<0.001$; Figure 3$)$. We found no effect of parity or heat stress on lying bouts (nulliparous vs. multiparous animals: 11.6 vs. $13.1 \pm 0.7$ no. $/ \mathrm{d}$; $P=0.14$; no heat stress vs. heat stress: 13.0 vs. 11.7 \pm 0.7 no. $/ \mathrm{d} ; P=0.27$ ) or mean lying bout duration (nulliparous vs. multiparous animals: 47.5 vs. $51.9 \pm$
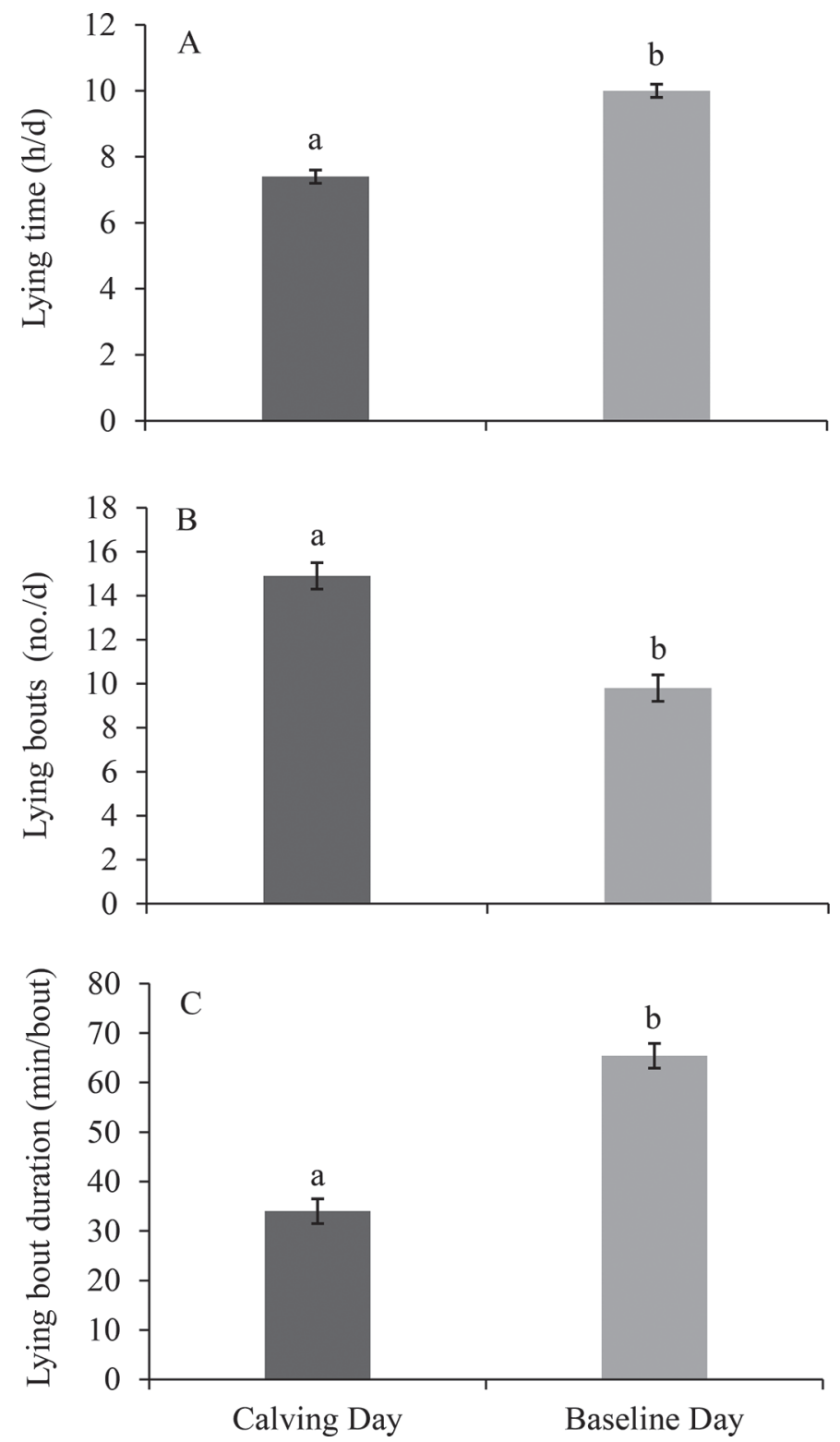

Figure 3. Least squares means $( \pm$ SEM) for (A) lying time, (B) number of lying bouts, and (C) lying bout duration for the calving and baseline days. Bars with different letters differed $(P \leq 0.05)$. 


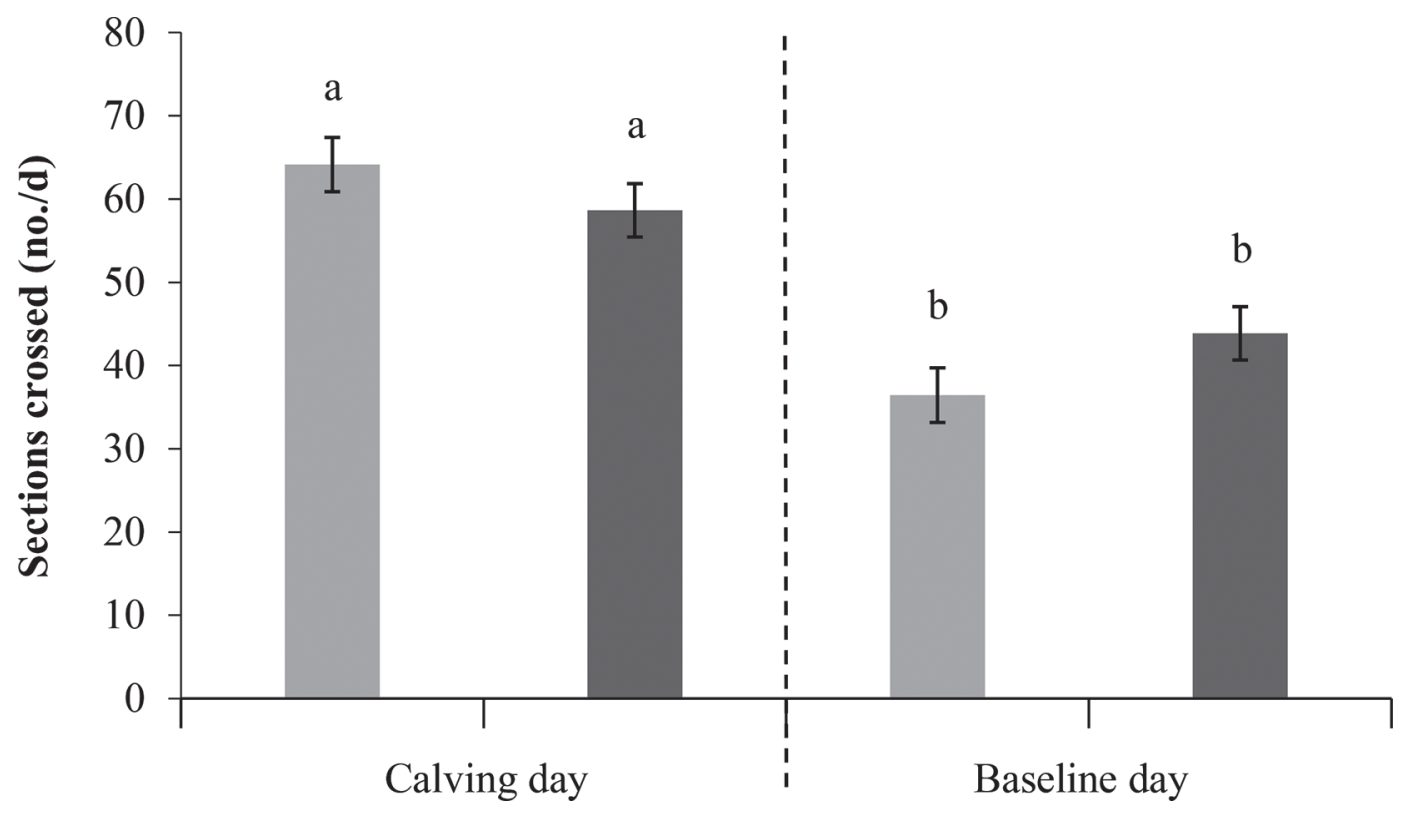

Figure 4. The number of sections crossed (mean $\pm \mathrm{SE}$ ) between successive 10-min scan samples for nulliparous heifers (light gray bars) and for primi- and multiparous cows (combined; dark gray bars) on calving and baseline days. Bars with different letters differed $(P \leq 0.05)$.

$2.8 \mathrm{~min} /$ bout; $P=0.27$; no heat stress vs. heat stress: 51.7 vs. $47.7 \pm 2.8 \mathrm{~min} /$ bout, respectively; $P=0.32$ ).

For number of steps taken, we found main effects of day (calving vs. baseline: 5,424 vs. $3,344 \pm 151$ steps/d; $P<0.001$ ), parity (nulliparous vs. multiparous; 4,835 vs. $3,932 \pm 154$ steps $/ \mathrm{d} ; P<0.001$ ), and heat stress conditions (heat stress vs. no heat stress; 4,826 vs. $3,943 \pm 153$ steps $/ \mathrm{d} ; P<0.001$ ), as well as an interactive effect of day, parity, and heat stress $(P<0.01)$. On the day of calving, nulliparous animals took more steps during heat stress conditions than during no heat stress conditions (7,313 vs. $5,031 \pm 315$ steps/d; $P<0.001)$; however, this was not the case for multiparous animals on the day of calving (4,725 vs. 4,629 \pm 285 steps/d; $P=0.81$ ), or parity on the baseline day (nulliparous: 3,138 vs. $3,860 \pm 308$ steps $/$ d; $P=0.11$; multiparous: 2,877 vs. $3,501 \pm 286$ steps $/ \mathrm{d} ; P=0.13$ ).

More sections were crossed on the calving day than on the baseline day (61 vs. $40 \pm 2$ no./d; $P<0.001$ ). Although we found no effect of parity on the number of sections crossed $(P=0.77)$, we did find a parity $\times$ day interaction (Figure 4; $P<0.05$ ). We found no effect of heat stress conditions on the number of sections crossed (heat stress vs. no heat stress: 50 vs. $51 \pm 2$ no./d; $P$ $=0.71)$.

\section{DISCUSSION}

Our objectives were to (1) describe the calving location of dairy cattle given access to a pasture and barn; (2) determine the factors associated with calving location; and (3) compare the lying and exploratory behavior of cows in the $24 \mathrm{~h}$ before calving and a previous (baseline) day. We found that calving location was affected by parity and THI; heifers and those calving when THI was 68 or less were most likely to seek areas of natural forage than the barn. In addition, lying time and lying bout duration were lower on the calving day than on a pre-calving baseline day. The number of lying bouts, the number of steps taken, and the number of sections of the environment crossed were higher on the calving day than on the baseline day.

\section{Calving Location Preference}

Approximately one-third of animals in the study calved in the barn (39\%), one-third in the area of open pasture $(26 \%)$, and one-third in the area of pasture with natural forage cover (35\%). Although these percentages were similar, both the barn and the area of natural forage were significantly smaller in size compared with the area of open pasture. Regardless of where animals chose to calve, they spent more time in their calving section on the day of calving compared with the baseline day. These findings were in agreement with other studies that gave cows access to both pasture and a sheltered area such as a barn (Edwards, 1983; Lidfors et al., 1994; Flörcke and Grandin, 2014). Lidfors et al. (1994) observed that 9 of 14 beef and dairy cattle sought out areas of natural forage cover 
(i.e., trees and small bushes) and dry, soft ground to give birth, whereas the other 5 animals calved in or near a covered barn. Edwards (1983) provided cows with a straw-covered yard and an area of open pasture (with no natural forage) and found that $22 \%$ of cattle selected the pasture to give birth. The use of pasture to calve may be affected by the amount of natural forage available to the cows (Rørvang et al., 2018b); in our study, cows and heifers had access to an area of pasture with no cover, and an area with dense vegetation at its far end. Cows and heifers may have been attracted to the area with dense vegetation, because this provided them an area to hide themselves and their newborns. In comparison, Edwards (1983) showed fewer cows using an area of pasture to calve when a barn was available ( $22 \%$ vs. $61 \%$ in our study; $26 \%$ in open pasture and $35 \%$ in the area of natural forage). The pasture area provided in Edwards (1983) provided less dense vegetation, so it may have been less attractive for cattle to leave the barn to give birth. These results suggest that if producers provide pasture to dairy cows to give birth, some area of natural or artificial cover (such as a barn) may be beneficial.

Nulliparous heifers were more likely to calve in the natural forage cover than in the barn. Lidfors et al. (1994) reported similar findings, where the majority of nulliparous heifers calved in natural forage cover, and multiparous cows calved in both the natural forage cover and barn. It is unclear why heifers were more likely to use the area of natural forage cover than older animals. One explanation could be the social status of the animals: younger animals may have been of lower social rank, and thus attempted to escape older animals during labor by moving to the furthest section of the pasture. Neave et al. (2017) reported that in an indoor freestall barn, nulliparous heifers were replaced at the feedbunk more often than multiparous cows during the weeks before calving, suggesting that they were of lower social rank in a mixed-parity pen. Rørvang et al. (2018a) found that when animals were kept in an indoor group maternity pen with access to individual pens for seclusion during calving, more dominant cows were more likely to separate at calving than more subordinate cows. Dominant animals may be able to control resources better than animals of lower social rank; the barn may bave been considered a resource by older animals in our study. Future studies should focus on understanding what role social hierarchy has on calving location preferences.

The use of barn, open pasture, or natural forage for calving was affected by THI. Cattle were more likely to calve in the pasture area with natural forage cover than the barn when the THI was 68 or less, suggesting that cows preferred the barn when the THI was high.
Similarly, Legrand et al. (2009) reported that primiand multiparous cows spent less time on pasture and more time in a freestall barn as THI increased between 0800 and $2200 \mathrm{~h}$. Cattle may have chosen to calve in the barn when the THI was high, because the barn offered provided the most protection from solar radiation. Although the natural forage area may have offered shade, the exposed walk (with no shade) to reach the forage area may have deterred animals from reaching this area under high THI conditions. Further research is encouraged to determine the effect of cooling strategies on cows kept on pasture during parturition.

\section{Lying and Exploratory Behavior}

Cows and heifers spent approximately $2 \mathrm{~h}$ less time lying down and spent an average of 31.4 min less per lying bout on the day of calving compared with the baseline day. This finding agreed with those of other studies in which cows were kept on pasture (Black and Krawczel, 2016; Borchers et al., 2017; Rice et al., 2017; Duncan and Meyer, 2019; Hendriks et al., 2019) or in indoor maternity pens (Huzzey et al., 2005; Miedema et al., 2011; Jensen, 2012) before calving. The lower lying time and bout duration on the day of calving may be an indication of pain due to uterine pressure and cervical dilation (Mainau and Manteca, 2011), or their natural instinct to distance themselves from the herd to find a secluded place to give birth (Lidfors et al., 1994; Rørvang et al., 2018b).

Nulliparous heifers spent $2 \mathrm{~h}$ less time lying per day than older cows. Sepúlveda-Varas et al. (2014) reported similar results for animals kept on pasture; nulliparous heifers spent $1 \mathrm{~h}$ less time lying than older cows during the 3 wk after calving. The reason for this difference in lying time on pasture is unclear. Lying times reported in our study for nulliparous $(7.6 \mathrm{~h} / \mathrm{d})$ and older animals $(9.7 \mathrm{~h} / \mathrm{d})$ both fell within the "normal" range reported in a recent review of pastured dairy cows (3.6 to 10.3 h/d; Kilgour, 2012). Some researchers have reported a parity effect on lying time before calving for cows kept indoors, and some have found no differences. For example, Neave et al. (2017) found no difference in lying time between nulliparous heifers and primi- and multiparous cows from 3 wk before to 3 wk after calving. In contrast, Calderon and Cook (2011) found an interaction between parity and day for lying time during the 3 wk before calving: lying time was higher for nulliparous heifers than for older animals during the 5 to $2 \mathrm{~d}$ before calving. Other authors have speculated that this difference in lying time may be driven by higher rumination time (Stone et al., 2017) or less disrupted rest patterns (Vasseur et al., 2012) in older animals than in younger animals. We suggest that this difference on pasture 
may also be driven by previous experience in the free stall; older cows spent more time in the free stall before the start of this study than nulliparous animals, where lying times are normally higher than on pasture. Older cows may have learned to spend more time lying when housed in the free stall, and this behavior carried over into the pasture. Farm animal behavior is affected by previous learned behaviors (Wechsler and Lea, 2007), and cows show consistency in lying behavior across time and environmental conditions (Müller and Schrader, 2005). Understanding how parity, previous experience, and other factors affect lying behavior in cows requires further investigation.

Regardless of the day relative to calving, cows and heifers that experienced mild to moderate heat stress conditions $(\mathrm{THI}>68$ and $\leq 79)$ spent $2 \mathrm{~h}$ less time lying down than those not experiencing heat stress conditions (THI $\leq 68$ ). To our knowledge, this is the first study to report the effect of THI on lying time for dry cows kept on pasture. Our results agreed with those of other studies of mid-lactation cows kept in indoor freestall pens (Cook et al., 2007; Allen et al., 2015), indoor loose housing (Zähner et al., 2004), and desert drylots (Allen et al., 2015). Indoors, cows decrease their lying time by about $30 \%$ when THI increases from 56.2 to 73.8 (Cook et al., 2007). Heat stress has various negative effects on cow welfare (reviewed by Polsky and von Keyserlingk, 2017); considerations should be made when keeping cows on pasture before calving to ensure abundant shade and cooling opportunities.

Cows and heifers made 5 more transitions from lying to standing per day on the day of calving compared with the baseline day. This finding was in agreement with previous studies in which cows were kept on pasture (Black and Krawczel, 2016; Borchers et al., 2017; Rice et al., 2017) or in indoor maternity pens (Miedema et al., 2011; Jensen, 2012). Black and Krawczel (2016) compared the lying behavior of cows on pasture with those indoors and found that both pasture and indoor cows had higher lying bouts on the day of calving than on previous days, but the cows on pasture had fewer lying bouts than those kept indoors on the day of calving. The authors suggested that cows may be more comfortable on pasture and transition less frequently between standing and lying than those kept indoors. Rørvang et al. (2018b) suggest that lying bouts may also be a sign of frustration as cows try to seek a suitable place to give birth, because cows kept indoors may be more frustrated than those kept on pasture. In agreement with this idea, in the present study the lying bouts on the day of calving (14.9 no./d) were similar to those found by Black and Krawczel (2016) in cows kept on pasture (14.0 no./d), and lower than cows kept indoors
(21.8 no./d, Huzzey et al., 2005; 24 no./d, Jensen, 2012).

Nulliparous heifers took more steps on the day of calving when the THI was high (THI $>68$ and $\leq 79$ $=$ heat stress) than when it was low $(\mathrm{THI} \leq 68)$, but this was not the case for primi- and multiparous cows. Existing knowledge is limited about the effect of both parity and THI on the steps taken by dairy animals before calving. In a study of beef cows and heifers, Duncan and Meyer (2019) found no effect of parity on the number of steps taken, but THI was not considered as a factor in the model. It is not clear why heifers took more steps on the day of calving when THI was high; perhaps they had a harder time thermoregulating due to their size and may have been more restless when temperature and humidity increased.

Regardless of parity, cows and heifers crossed 20 more sections in the $24 \mathrm{~h}$ before calving compared with the baseline day, suggesting that they engaged in more exploratory behavior as calving approached. Both beef and dairy cows on rangeland will leave the herd to seek an isolated, dry, elevated area to give birth (Lidfors et al., 1994; Flörcke and Grandin, 2014). Thus, the cows in our study may have been crossing multiple sections on the day of calving to find a suitable place to give birth. Although it is less studied in dairy cows, movement analysis using radiotelemetry (GPS, global positioning satellite) data has been used to predict parturition in wild elk (Dzialak et al., 2011), caribou (DeMars et. al., 2013), and moose (Severud et al., 2015). For example, Severud et al. (2015) found that female moose traveled long distances (an average of $5.4 \mathrm{~km}$ ) approximately $14 \mathrm{~h}$ before calving, and then stayed in one area to give birth; dams and their calves then remained in a postparturient area for approximately $6 \mathrm{~d}$ with their neonates before rejoining their groups. Anecdotally, some animals in our study were seen walking back and forth across the pasture as calving approached, perhaps maintaining a motivation to walk long distances before labor. The reason for this movement is not well understood, but could be related to increasing exercise to improve labor outcomes (Black et al., 2017) or selecting calving areas that reduce predation risk and disturbance from other dams.

\section{CONCLUSIONS}

When cows and heifers were given access to a beddedpack barn and a 2.1-acre pasture, heifers and those calving when THI was 68 or less were more likely to calve in the natural forage cover than in the barn. Cows and heifers had lower lying time and lying bout durations, as well as higher lying bouts, steps, and exploratory 
behavior in the $24 \mathrm{~h}$ before calving compared with a previous baseline day. Lying time and the number of steps taken were also affected by parity and THI. These results provide evidence that cows and heifers differ in their preference for calving location, and they actively explore their environments when seeking a place to give birth. When calving outdoors, cows should be given ample access to shade to reduce any negative effects of heat stress on their behavior.

\section{ACKNOWLEDGMENTS}

This work is supported by USDA-NIFA-AFRI (Agriculture and Food Research Initiative) Foundation (grant no. 2016-67015-24734) from the USDA National Institute of Food and Agriculture (Washington, DC). We thank the farm staff at the University of Tennessee's Little River Animal and Environmental Unit for their assistance during the project. The authors have not stated any conflicts of interest.

\section{REFERENCES}

Allen, J. D., L. W. Hall, R. J. Collier, and J. F. Smith. 2015. Effect of core body temperature, time of day, and climate conditions on behavioral patterns of lactating dairy cows experiencing mild to moderate heat stress. J. Dairy Sci. 98:118-127. https://doi.org/10 $.3168 /$ jds.2013-7704.

Black, R. A., and P. D. Krawczel. 2016. A case study of behaviour and performance of confined or pastured cows during the dry period. Animals (Basel) 6:41. https://doi.org/10.3390/ani6070041.

Black, R. A., B. K. Whitlock, and P. D. Krawczel. 2017. Effect of maternal exercise on calf dry matter intake, weight gain, behavior, and cortisol concentrations at disbudding and weaning. J. Dairy Sci. 100:7390-7400. https://doi.org/10.3168/jds.2016-12191.

Borchers, M. R., Y. M. Chang, K. L. Proudfoot, B. A. Wadsworth, A. E. Stone, and J. M. Bewley. 2017. Machine-learning-based calving prediction from activity, lying, and ruminating behaviors in dairy cattle. J. Dairy Sci. 100:5664-5674. https://doi.org/10.3168/jds .2016-11526.

Calderon, D. F., and N. B. Cook. 2011. The effect of lameness on the resting behavior and metabolic status of dairy cattle during the transition period in a freestall-housed dairy herd. J. Dairy Sci. 94:2883-2894. https://doi.org/10.3168/jds.2010-3855.

Cook, N. B., R. L. Mentink, T. B. Bennett, and K. Burgi. 2007. The effect of heat stress and lameness on time budgets of lactating dairy cows. J. Dairy Sci. 90:1674-1682. https://doi.org/10.3168/ jds.2006-634.

DeMars, C. A., M. Auger-Méthé, U. E. Schlägel, and S. Boutin. 2013. Inferring parturition and neonate survival from movement patterns of female ungulates: A case study using woodland caribou. Ecol. Evol. 3:4149-4160. https://doi.org/10.1002/ece3.785.

Duncan, N. B., and A. M. Meyer. 2019. Locomotion behavior changes in peripartum beef cows and heifers. J. Anim. Sci. 97:509-520. https://doi.org/10.1093/jas/sky448.

Dzialak, M. R., S. M. Harju, R. G. Osborn, J. J. Wondzell, L. D. Hayden-Wing, J. B. Winstead, and S. L. Webb. 2011. Prioritizing conservation of ungulate calving resources in multiple-use landscapes. PLoS One 6:e14597. https://doi.org/10.1371/journal.pone .0014597 .

Edwards, S. 1983. The behaviour of dairy cows and their newborn calves in individual or group housing. Appl. Anim. Ethol. 10:191198. https://doi.org/10.1016/0304-3762(83)90140-2.
Flörcke, C., and T. Grandin. 2014. Separation behavior for parturition of Red Angus beef cows. J. Anim. Sci. 4:43-50. https://doi.org/10 .4236/ojas.2014.42007.

Hendriks, S. J., C. V. C. Phyn, S. A. Turner, K. M. Mueller, B. KuhnSherlock, D. J. Donaghy, J. M. Huzzey, and J. R. Roche. 2019. Lying behavior and activity during the transition period of clinically healthy grazing dairy cows. J. Dairy Sci. 102:7371-7384. https:// doi.org/10.3168/jds.2018-16045.

Huzzey, J. M., M. A. G. von Keyserlingk, and D. M. Weary. 2005. Changes in feeding, drinking, and standing behavior of dairy cows during the transition period. J. Dairy Sci. 88:2454-2461. https:// doi.org/10.3168/jds.S0022-0302(05)72923-4.

Jensen, M. B. 2012. Behaviour around the time of calving in dairy cows. Appl. Anim. Behav. Sci. 139:195-202. https://doi.org/10 .1016/j.applanim.2012.04.002.

Kilgour, R. J. 2012. In pursuit of "normal": A review of the behaviour of cattle at pasture. Appl. Anim. Behav. Sci. 138:1-11. https://doi .org/10.1016/j.applanim.2011.12.002.

Legrand, A. L., M. A. Von Keyserlingk, and D. M. Weary. 2009. Preference and usage of pasture versus free-stall housing by lactating dairy cattle. J. Dairy Sci. 92:3651-3658. https://doi.org/10.3168/ jds.2008-1733.

Lidfors, L. M., D. Moran, J. Jung, P. Jensen, and H. Castren. 1994. Behaviour at calving and choice of calving place in cattle kept in different environments. Appl. Anim. Behav. Sci. 42:11-28. https:/ /doi.org/10.1016/0168-1591(94)90003-5.

Lombard, J. E., F. B. Garry, S. M. Tomlinson, and L. P. Garber. 2007. Impacts of dystocia on health and survival of dairy calves. J. Dairy Sci. 90:1751-1760. https://doi.org/10.3168/jds.2006-295.

Mainau, E., and X. Manteca. 2011. Pain and discomfort caused by parturition in cows and sows. Appl. Anim. Behav. Sci. 135:241251. https://doi.org/10.1016/j.applanim.2011.10.020.

Mattachini, G., E. Riva, C. Bisaglia, J. C. A. M. Pompe, and G. Provolo. 2013. Methodology for quantifying the behavioral activity of dairy cows in freestall barns. J. Anim. Sci. 91:4899-4907. https:// doi.org/10.2527/jas.2012-5554.

Mee, J. F. 2008. Prevalence and risk factors for dystocia in dairy cattle: A review. Vet. J. 176:93-101. https://doi.org/10.1016/j.tvjl .2007.12.032.

Miedema, H. M., M. S. Cockram, C. M. Dwyer, and A. I. Macrae. 2011. Changes in the behaviour of dairy cows during the $24 \mathrm{~h}$ before normal calving compared with behaviour during late pregnancy. Appl. Anim. Behav. Sci. 131:8-14. https://doi.org/10.1016/ j.applanim.2011.01.012.

Müller, R., and L. Schrader. 2005. Individual consistency of dairy cows' activity in their home pen. J. Dairy Sci. 88:171-175. https:/ /doi.org/10.3168/jds.S0022-0302(05)72675-8.

NOAA (National Oceanic Atmospheric Administration). 1976. Livestock Hot Weather Stress. Operations Manual Letter C-31-76. Dept. of Commerce, NOAA, Natl. Weather Serv. Central Reg. NOAA, Kansas City, MO.

NRC (National Research Council). 2001. Nutrient Requirements of Dairy Cattle. 7th rev. ed. Natl. Acad. Press, Washington, DC.

Neave, H. W., J. Lomb, M. A. G. von Keyserlingk, A. Behnam-Shabahang, and D. M. Weary. 2017. Parity differences in the behavior of transition dairy cows. J. Dairy Sci. 100:548-561. https://doi.org/ $10.3168 / j d s .2016-10987$.

Overton, T., and M. Waldron. 2004. Nutritional management of transition dairy cows: Strategies to optimize metabolic health. J. Dairy Sci. 87:E105-E119. https://doi.org/10.3168/jds.S0022 -0302(04)70066-1.

Polsky, L., and M. A. G. von Keyserlingk. 2017. Invited review: Effects of heat stress on dairy cattle welfare. J. Dairy Sci. 100:8645-8657. https://doi.org/10.3168/jds.2017-12651.

Proudfoot, K. L., M. B. Jensen, D. M. Weary, and M. A. von Keyserlingk. 2014a. Dairy cows seek isolation at calving and when ill. J. Dairy Sci. 97:2731-2739. https://doi.org/10.3168/jds.2013-7274.

Proudfoot, K. L., D. M. Weary, and M. A. G. von Keyserlingk. 2014b. Maternal isolation behavior of Holstein dairy cows kept indoors. J. Anim. Sci. 92:277-281. https://doi.org/10.2527/jas.2013-6648. 
Rice, C. A., N. L. Eberhart, and P. D. Krawczel. 2017. Prepartum lying behavior of Holstein dairy cows housed on pasture through parturition. Animals (Basel) 7:32. https://doi.org/10.3390/ani7040032.

Rørvang, M. V., M. S. Herskin, and M. B. Jensen. 2018a. The motivation-based calving facility: Social and cognitive factors influence isolation seeking behaviour of Holstein dairy cows at calving. PLoS One 13:e0191128. https://doi.org/10.1371/journal.pone.0191128.

Rørvang, M. V., B. L. Nielsen, M. S. Herskin, and M. B. Jensen. 2018b. Prepartum maternal behavior of domesticated cattle: A comparison with managed, feral, and wild ungulates. Front. Vet. Sci. 5:45. https://doi.org/10.3389/fvets.2018.00045.

Sepúlveda-Varas, P., J. M. Huzzey, D. M. Weary, and M. A. G. von Keyserlingk. 2013. Behaviour, illness, and management during the periparturient period in dairy cows. Anim. Prod. Sci. 53:988-999. https://doi.org/10.1071/AN12286.

Sepúlveda-Varas, P., D. M. Weary, and M. A. G. von Keyserlingk. 2014. Lying behavior and postpartum health status in grazing dairy cows. J. Dairy Sci. 97:6334-6343. https://doi.org/10.3168/ jds.2014-8357.

Severud, W. J., G. D. Giudice, T. R. Obermoller, T. A. Enright, R. G. Wright, and J. D. Forester. 2015. Using GPS collars to determine parturition and cause-specific mortality of moose calves. Wildl. Soc. Bull. 39:616-625. https://doi.org/10.1002/wsb.558.

Stone, A. E., B. W. Jones, C. A. Becker, and J. M. Bewley. 2017. Influence of breed, milk yield, and temperature-humidity index on dairy cow lying time, neck activity, reticulorumen temperature, and rumination behavior. J. Dairy Sci. 100:2395-2403. https://doi .org/10.3168/jds.2016-11607.
Telezhenko, E., M. A. G. von Keyserlingk, A. Talebi, and D. M. Weary. 2012. Effect of pen size, group size, and stocking density on activity in freestall-housed dairy cows. J. Dairy Sci. 95:3064-3069. https://doi.org/10.3168/jds.2011-4953.

Vasseur, E., J. Rushen, D. B. Haley, and A. M. de Passillé. 2012. Sampling cows to assess lying time for on-farm animal welfare assessment. J. Dairy Sci. 95:4968-4977. https://doi.org/10.3168/ jds.2011-5176.

Wechsler, B., and S. E. G. Lea. 2007. Adaption by learning: Its significance for farm animal husbandry. Appl. Anim. Behav. Sci 108:197-214. https://doi.org/10.1016/j.applanim.2007.03.012.

Zähner, M., L. Schrader, R. Hauser, M. Keck, W. Langhans, and B. Wechsler. 2004. The influence of climatic conditions on physiological and behavioural parameters in dairy cows kept in open stables. J. Anim. Sci. 78:139-147. https://doi.org/10.1017/ S1357729800053923.

\section{ORCIDS}

P. D. Krawczel ๑ https://orcid.org/0000-0002-9867-2280

H. M. Dann () https://orcid.org/0000-0002-7372-7011

B. Whitlock (1) https://orcid.org/0000-0001-7247-0982

K. L. Proudfoot (i) https://orcid.org/0000-0001-5877-2431 